\title{
Bilimkurgu Türünde Yapısal Kavramlar ve Değişim Arrival Filmi Örneği
}

\author{
Özcan DEMIR \\ Gaziantep Üniversitesi, Güzel Sanatlar Fakültesi, Sinema ve Televizyon Bölümü, Gaziantep \\ ozcandd@hotmail.com \\ ORCID ID: https:/orcid.org/0000-0001-9273-7672
}

\begin{tabular}{|c|c|c|}
\hline Araştırma Makalesi & & DOI: 10.31592/aeusbed.61 \\
\hline Geliş Tarihi: 04.09.2019 & Revize Tarihi: 18.03 .2020 & Kabul Tarihi: 19.03. \\
\hline
\end{tabular}

\section{ÖZ}

Tür filmleri biçimsel ve tematik özellikleriyle benzerlik gösteren filmlerdir. Bilimkurgu filmleri, teknoloji, uzay, kontrolden çıkmış deneyler ve robotlar gibi temalarıyla izleyicisine ulaşmaktadır. Bilimkurgu filmleri, bilimsel gerçeklikten kurgusal evrenini oluşturmak için yararlanmaktadırlar. Dünya savaşları ile kültürel ve siyasi dönüşümler öncesi koşullardan içerik yönüyle etkilenmişlerdir. Kültürel ve siyasi göndermeleri olan ya da propaganda amaçlı bilimkurgu filmlerinden bahsetmek mümkündür. Tüm tür filmlerinin olduğu gibi bilimkurgu türü de diğer türlerle etkileşim içindedir. Bilimkurgu filmlerinin etkileşim içinde olacağı türler kültür endüstrisinin ticari bir tercihidir. Toplumsal koşullar ve yönetmenlerin özgün biçemlerinin de filmin hayata geçirilmesinde etkili olduğunu söylemek mümkündür. Bu çalışmada, Denis Villeneuve tarafindan yönetilen Arrival (Geliş) (2016), bilim kurgu türünün diğer türlerle etkileşimi bağlamında değerlendirilmiş ve türün sosyal kültürel değişimin sürekliliğinde değişip değişmediğinin belirlenmesi amaçlanmıştır. Arrival filminin tür analizinde metin çözümlemesi tekniğinden yararlanılmıştır. Türün yapısal değişiminin tespitinde Derrida'nın yapısöküm tekniği kullanılmıştır. Yapısökümün, metin düzeyinde mevcut olan alternatif anlamların tespitine imkân veren yaklaşımı yol gösterici olmuştur. Bu nedenle çalışmada, yapısökümdeki 'differance' kavramının öngördüğü kavramsal tanımlama pratiğinin bilimkurgu türündeki yapısal değişimi açıklamada kullanılması amaçlanmıştır. Çalışma sonucunda, Arrival filminin yönetmeni Denis Villeneuve'ün biçemini içerik ve atmosfer boyutuyla yansıttığı değerlendirmesi yapılmıştır. Filmin, Derrida'nın yapısökümcü yaklaşımı ışığında yapılan analizi bağlamında; bilimkurgu türünün alışılagelmiş kabullerini yeniden tanımladığını söylemek mümkündür. Arrival filminin metinsel düzeyde, dünya ülkelerinin işbirliğinin, savaş ve çatışmadan daha değerli olduğu fikrini işlediği sonucuna ulaşılmıştır.

Anahtar Kelimeler: Sinema, tür, bilimkurgu, Denis Villeneuve, Arrival.

\section{Structural Concepts and Change in Science Fiction The Sample of Arrival Film}

\begin{abstract}
Genre films have similar characteristics formally and thematically. Science fiction films have themes such as technology, space, scientific experiments and robots. They use science to form fictional reality. They're affected by the context of the world wars and the circumstances formed before cultural and politic revolutions. There are science fiction films having cultural, political references or prepared for propaganda. They interact with other genres. The culture industry commercially decides which genres they interact more with. The social circumstances and the directors' original style effect the production. In this study, Denis Villeneuve's Arrival movie (2016) was evaluated in the context of science fiction genre's interaction with other genres and it is aimed to find out if the genre changed in the continuum of social and cultural change. Text analysis technique was used in the genre analysis of Arrival. Derrida's method of deconstruction was used to determine the structural change of the genre. The approach of deconstruction, which enables the identification of alternative meanings that exist at the text level is guiding. For this reason in this study, it is aimed to use the conceptual definition practice envisaged by the concept of differance in deconstruction to explain the structural change in science fiction genre. As a result of the study, it is concluded that Arrival film reflects the style of its director Denis Villeneuve in terms of content and atmosphere. In the context of the analysis of the film made according to Derrida's deconstructive approach; it is possible to say that Arrival's approach to the science fiction genre has redefined its usual admissions. It is concluded that Arrival defends the idea that the cooperation of the countries of the world is more valuable than war and conflict at textual level.
\end{abstract}

Keywords: Cinema, genre, science fiction, Denis Villeneuve, Arrival. 


\section{Giriş}

Kurmaca filmler, sinema endüstrisi içerisinde biçimsel ve içerik özellikleri kapsamında türler dâhilinde sınıflandırılabilmektedir. "Tür sözcüğü dilimizde, Fransızca kökenli genre sözcüğünün karşılığı olarak kullanılmaktadır. Aslında genre daha çok cins (aralarında benzer, ortak özellikler bulunan varlık ve nesnelerin topluluğu) anlamına gelmektedir. Ancak, sanat alanına ilişkin bir terim olan genre için türün kullanılması daha doğrudur" (Abisel, 1995, ss. 13-14). Tür filmleri, "çeşitli yönlerden benzerlik gösteren, yapıları birbirini andıran, ortak nitelik, özellik ve öğeler taşıyan filmlerin kümelendirilmesinden oluşur. Bu sınıflandırmada, belli bir konuyu ele alış açısı, konuyu işlerkenki tutum, kullanılan gereç filmin çeşitli öğelerinin kullanılış biçimi göz önüne alınır" (Özön, 1985, s. 145).

Tür filmlerinin tematik benzerlikleri izleyicilerin belirli konulardaki yapımları takip etmesini sağlamaktadır. Filmlerde kullanılan araç-gereçler, çekim mekânları, kostümler, aydınlatma, kamera açıları ve kurgu anlayışları her türün kendi özelliklerini oluşturmada etkili faktörlerdir. Tür filmi izleyicisi daha filme gitmeden yapımın adı, kısa tanıtım yazısı, afişi, yönetmeni hatta oyuncularının adlarını gördüğünde ne izleyeceği hakkında fikir sahibi olabilmektedir. Bu durum, ticari sinema sektörü özellikle Hollywood açısından filmlerin dağıtım ve gösterim aşamalarında önemli avantajlar sağlamaktadır.

$\mathrm{Bu}$ anlamda, tür filmleri izleyicinin ön kabulleri ve tahminleri yardımıyla izlemeye karar verdikleri ve izlemeyi sürdürdükleri filmlerdir. "Janr filmi, bu umutları ve beklentileri oluşturur, daha sonra da bunları karşılayarak keyif verir. Janr filmlerini incelerken, öncelikle onlarla tekrar tekrar karşımıza çıkan motifleri ve temaları ayırt etmemiz gerekir” (Buckland, 2018, s. 136).

Hollywood'un kullandığı uylaşımlar ışığında melodram, western, müzikal, kara film, yol filmi ve bilimkurgu türlerinden bahsetmek mümkündür. Her türün kendine özgü yapıları, temaları, ikonografisi ve ortak üslup özellikleri bulunmaktadır. "Tür kavramı, filmlere ilişkin belirli kalıpları ve sınıflandırmaları yapmayı kolaylaştırsa da kendi içinde değişken bir tür olgusundan bahsetmek yerinde olacaktır. Filmleri tek bir tür başlığ1 altında değerlendirmek güçtür. Piyasa şartları ve filmlere özgü gereksinimler bağlamında türler arasında geçişkenlikler görülmektedir" (Corrigan, 2007, ss. 130-131). Western türüyle bilimkurgu türünün birleştiği Cowboys and Aliens (Kovboylar ve Uzaylılar) (2011) ya da Total Recall (Gerçeğe Çağrı) (2012) gibi polisiye bilimkurgu filmlerinden bahsetmek mümkündür. Türler de kendi içlerinde değişmektedir. Temalar, üslup özellikleri ve ikonografik özellikler bağlamında tarihsel süreç içerisinde tür filmlerinin değişikliğe uğradığını söylemek mümkündür. "Bir türe özgü filmler içerik, tema ve set tasarımı açısından türe özgü diğer filmlerle; diğer türlere dâhil filmlerden çok daha fazla ortak özellik paylaşırlar" (Hunter ve Smith, 2015).

"Bir janrın "dışsal formu” görsel öğeleri içerirken "içsel biçim”i bu görsel öğeleri açılayan araçtır. Yönetmen ikonografinin sağladığı kaynakları, onları tanıdıklar ve yenilikleri birleştiren yöntemlerle yeniden birleştirerek harekete geçirir" (Stam, 2014, s. 137). Tür filmleri, ortak biçimsel ve içerik özellikleriyle kendi izleyici kitlelerine sahiptir. Belirli zevkleri olan izleyici kitlesini çekmeleriyle Hollywood için izleyiciye ulaşan ürünler olmuşlardır. Sanatsal öncelikleri olmamasına karşın anlatı sinemasının temel teknik ve sinematografik esaslarını paylaşmakta olduklarını söylemek mümkündür. İzleyicilerini sinemaya çeken gerçekçi teknolojik özellikleri ve efektleriyle "sinema sektörü içinde daha sonraki dönemlerde hayata geçecek ciddi, sanatsal, entelektüel çalışmaların dramatik, teknik, estetik vb. altyapılarının oluşması için artıları ve eksileriyle ön laboratuar çalışmaları niteliğindedir" (Onur, 2011, s. 44).

Tür filmleri arasında en çok tekrarlanan ve izleyicinin ilgisini çekenlerden bir tanesinin bilimkurgu olduğunu söylemek mümkündür. Teknoloji ve bilimsel gelişmelerle etkileşim halindeki bir tür olarak değerlendirilebilir. Bilimkurgu metninin temel karakteristiği mevcut bilimsel, teknolojik ve sosyolojik gelişmeler ile ilgili spekülasyon, çıkarım ya da yorumları içeren metinler olmalarıdır (Calvin, 2014). Yapımlarda bu hedefi gerçekleştirmek amacıyla bilimsel bir dil kullanılmakta, özel efektlere başvurulmakta ya da mizansen öğeleri teknolojik temayı çağrıştıracak biçimde 
düzenlenmektedir. Filmlerin görüntü öğeleri kadar ses öğeleri de oluşturulan senaryoyu destekleyici biçimde kurgulanmaktadır. Bilimkurgu filmlerinde yapılmaya çalışılan çoğunlukla alternatif bir evren oluşturulması, üstün teknoloji ile alışılagelmiş dünya tasarımının değiştirilmesi ya da yaygın bilinen bilimsel gerçeklerden hareketle alternatif gerçeklik tasvirleri oluşturmaktır. Bilimkurgu türünde; "Piers D. Britton'a göre, bilimsel fizik kurallarından ziyade, seyircinin benzer bir fenomenle ilgili, birebir yaşayarak veya dolaylı yoldan edindiği kişisel deneyimini çağrıştıran 'genişletilmiş sağduyu'nun inandırıcı çeşitlemeleriyle donatılmış görsel ve işitsel tasarıma da yaslanır” (Bould, 2015, s. 18).

Bilimkurgu türü, kontrolden çıkmış bilimsel deneyler, uzaylı istilası ya da zaman yolculuğu gibi farklı temaları işleyebilmektedir. Türün örnekleri sıklıkla çatışma ve savaş öyküleri sunmaktadır. Filmlerin konu aldıkları çatışmalar bilimsel deneylerde insanüstü özelliklere kavuşturularak kontrolden çıkmış yaratıklar, dünya dışı yaratıklarla ya da uygarlıklarla yapılan savaşlar olabilmektedir. Bilimkurgu türünün pek çok örneğinde görüldüğü gibi konu alınan mücadele ya da durum gerçek dünyadan ve günlük hayattan uzak görünse de izleyicilerin gerçekliklerine göndermeler içerebilmektedir. "Çoğu durumda, askeri bilim kurgudaki hiper-kurgu dünyaları, savaşlar ve karakterler alegorik bir ilham kaynağı olarak gerçek dünyadaki benzerlere sahipti” (Forrest, Barfield, ve Barbier, 2013).

Tür filmlerinin, yinelemelere dayalı doğası popüler kültürün de temel niteliklerindendir. " $\mathrm{Bu}$ halleriyle tür filmlerini popüler kültür ürünleri olarak nitelemek mümkündür. Tür sineması seyircisine kitlesel düzeyde ulaşabilmektedir. Bu nedenle, popüler kültüre yönelik çalışmalarda tür filmleri önemli bir yere sahiptir" (Abisel, 1995, s. 10). "Sinemada türler, doğası gereği, sosyololojik, ideolojik, tarihsel, göstergebilimsel, psikanalitik, bilişsel yaklaşımlar ile feminist ideolojinin dikkat çektiği kavramların uyarlanabildiği, çok özellikli bir alanı işaret etmektedir" (Kabadayı, 2014, s. 102). Tüm popüler kültür ürünlerinde olduğu gibi tüm filmlerinin analizi de üretildiği toplumdaki dinamikler hakkında fikir verebilmesi ile araştırma konusu olmuştur.

Tür filmlerinin üretim gerekçeleri farklı bakış açılarıyla açıklanmıştır. Adorno'ya göre "kitle kültürü" ve "kültür endüstrisi" kavramları birbirinden farklıdır. "Kitle kültürü, toplumun ürettiği kültürü; kültür endüstrisi kavramı ise endüstrinin ürettiği kitlelere sunduğu kültürü anlatmaktadır. Kitle kültürü, standartlaştırmaya ve yaygınlaştırmaya dayalıdır" (Adorno ve Rabinbach, 1975, s. 12). "Kültür endüstrisi yapısında, tüketicinin tasnif edeceği hiçbir şey kalmamıştır. Yaratıcılık için hiçbir alan bırakılmamıştır. Her şey en küçük ayrıntısına kadar uygun bir şekilde biçimlendirilmiştir" (Erdoğan ve Alemdar, 2002, s. 411). Tür sinemasının sunduğu içerikle kültür endüstrisinin bir ürünü olarak incelenmesi mümkündür.

Bunun yanında, janr eleştirileri arasında film içeriklerinin toplumu anlamanın yolu olabileceğini savunan görüşler de mevcuttur. Film içerikleri, "bir toplumun temel sorunlarını, anksiyetelerini, zorluklarını, endişelerini ve daha genel olarak değerlerini, toplumun üyelerinin bu temel sorunlarla nasıl başa çıkmaya çalıştığını yansıtır. Janr filmi, izleyicilerin değinilmesini beklediği bu sorunlara değinmesi halinde tatmin edicidir" (Buckland, 2018, s. 136). Sözkonusu değerlendirmelere bakıldığında tür filminin topluma dayatılan davranış kalıplarının yansıtıldığı ürünler ya da toplumun davranış kalıplarının sergilendiği ürünler olduğunu savunan görüşler olduğunu söylemek mümkündür. Tür analizi yönteminden elde edilecek sonuçlar açısından bakılacak olursa, izleyicinin tür filmi izlemesinden kaynaklanan doyum, egemen ideolojinin sunduklarının olumlanması ve yeni içeriklerin izlenmesi ya da izleyicinin kültürel kabullerinin yansıması düzeyinde olabilir. Her koşulda tür filmleri ile kitle arasında bir bağlantı olduğunu söylemek mümkündür. Langford'a göre; "türler, film üretim ve tüketimlerinin ve bunların kültür ve toplumla yakın ilişkilerinin anlaşılmasında çok önemli araçlardır" (aktaran Kabaday1, 2014, s. 104).

"Sinemacılar, bir set kurduğunda, kamerayı belirli konumlara yerleştirdiklerinde, oyunculara belirli şekillerde rol verdiklerinde ve eldeki çekim yığınlarını tutarlı bir anlatı oluşturacak biçimde bir araya getirdiklerinde sadece bir öykü anlatmış olmazlar, ayrıca anlam da yararmış olurlar" (Ryan ve Lenos, 2012, s. 1). Toplumsal, endüstriyel ve metinsel süreçlerin etkili olduğu türlerin üretiminde, ürünlerin analizi aşamasında da filme bir metin olarak bakan göstergebilimsel yaklaşıma ve toplumsal 
ve ideolojik alanda değerlendirme yapabilmek için sosyolojik bakışlara ihtiyaç olduğunu söylemek mümkündür.

Tür filmlerini ve özelinde bilimkurgu türündeki yapımları biçimsel ve içerik yönleriyle analiz etmek mümkündür. Christian Metz'e göre film çözümlemesi aşamasında; “imgeler ve sıralanma biçimleri, söylenen sözler, işitilen gürültüler, kişiliklerin giysileri, davranışları, yüz ifadeleri, belli psikanalitik, toplumbilimsel ya ideolojik simgelerin olası varlığından oluşan gösterenler (biçim) ve kişiliklerin sergiledikleri psikoloji, filmin toplumsal içeriği, yönetmenin ideolojik mesajından oluşan gösterilenlerden (öz) bahsetmek mümkündür" (Metz, 2012, s. 91). Christian Metz'in film çözümlemesi konusundaki yöntem önerisinin ilk bölümünde vurguladığ 1 ve terminolojik karmaşaya dikkat çektiği bu tespitlerde filmin çok katmanlı incelenmesi gereğine vurgu yaptı̆̆ını söylemek mümkündür.

Tür filmlerinin analizinde de filmin biçimsel ve içerik özelliklerinin ele alınması uygulanan yöntemler arasındadır. "Bu kapsamda, türlerin tarihçesi, temel karakteristik özellikleri, ikonografiler, üretim biçimleri, yıldız oyuncu politikaları, seyirci beklentileri ve alımlama süreçleri, ideolojileri ve yönetmenlerinin auteur özellikleri, alttürleri ve türler arasındaki geçişkenlikleri ve türlerin zamana yönelik toplumsal karşılıkları ele alınmaktadır" (Kabadayı, 2014, s. 105). "Auteur-yapısalcılık, tür eleş̧irisinden etkilenmiş ve ona duyulan ilgi bağlamında ilerlemiştir. Peter Wollen'ın auteuryapısalcılık analizinde konu aldığı John Ford'un ürettiği yapımlarının çoğunun kovboy filmi türünde olduğunu tespit etmesi buna örnektir"' (Stam, 2014, s. 136).

Tür eleştirisi bağlamında kullanılabilecek araçlardan bir diğeri de post yapısalcı bir yaklaşım olan yapı-çözmedir (yapısöküm - deconstruction). Yapısalcılığa göre, "dilbilimdeki söze tekabül eden somut edebiyat yapıtlarından yola çıkarak bunların uyduğu sisteme (dile) ulaşmak şarttır; çünkü sistem ile tek tek yapıtlar arasındaki bağıntı, dilbilimde dil ile söz arasındaki bağıntının benzeridir" (Moran, 1999, s. 198). Michel Faucault, Roland Barthes, Jaques Lacan ve Jaques Derrida'nın önderlik ettiği post-yapısalcı1ık akımında Derrida'nın yazılarından gelen yapı-çözüm yöntemi kullanılmaktadır.

Dilsel anlamda inşa edilen bir metni (construction); "karmaşık tarihsel ve kültürel süreç olarak görme ve okuma ile ilgilidir. Eleştirel kuram sadece bir ilişkinin edebiyatta yansımasını değil, her tür sosyal ilişki biçimini analize çalışır. Yapısalcılık ve yapı-çözme her tür sosyal-metni analiz eder" (Erdoğan ve Alemdar, 2002, s. 354). Edebi yapıtın, belirli bir bakış açısı, dönemsel öngörüler ve kesin kavramsal tanımlar çerçevesinde değerlendirilmesi Derrida'nın batı felsefesine temel eleştirisini oluşturmaktadır. Batı felsefesinin tanımlamayıcı kavramsal örgütleme yaklaşımı farklılıklar ve zıtlıkların kavramsal düzeyde inşa edilmesiyle belirgin tanımlar yapılması düşüncesine dayanmaktadır. Derrida, bu anlayışın felsefi ihtiyaçların karşılanmasında yeterli olmadığ 1 düşüncesinden hareket etmiştir. "Zira artık dil ve dil tarafından üretilen kültür, sabit olan, zamana karşı direnen ve aynı kalan bir mevcudiyet varsayımından türetilemez. Bunun yerine belirleyici ölçütler artık fark, mevcut olmama ve anlamın ertelenmesi olacaktır (Rutli, 2016, s.58)." Bir eserdeki karşıtlıkların bulunması, metnin karşıtlıkların oluşturduğu yapılara göre yeniden kurulması, metni oluşturan ve alımlayan arasındaki nedensel ve uzamsal boşluktan kaynaklanan nedensizlikten yararlanan eleştiri yöntemidir. Yapı-çözmede; "birinci aşama bozma ikinci aşama ise yeniden inşa etme aşamasıdır. Birinci aşamada ele alınan metnin yapısı bozulur. İkinci aşamada ise bambaşka bir bağlamda metin tekrar inşa edilir. Her iki aşamada da malzeme, metni kuran kavram dağarcığından başka bir şey değildir (Rutli, 2016, s.63)."

Bilimkurgunun, sosyal ve kültürel bağlamlardan beslenen birtakım uylaşımlardan yararlanan bir tür olduğunu söylemek mümkündür. Uzay, zaman yolculuğu, teknolojik araçlar ve uzam bu uylaşımlar arasında yer almaktadır. Arrival (Geliş) (2016) filmindeki uzay, teknolojik araç-gereçler ve uzaylı öğeleri bilimkurgu türünün uylaşımları arasındadır. Klasik anlatının oluşturulmasında kullanılan dramaturjik karşıtlıklar bilimkurgu anlatısının oluşturulmasında da kullanılmaktadır. Derrida'nın yaklaşımıyla Arrival filmindenin metnindeki karşıtlıkların tespit edilmesi ve türün yeniden yapılandırılmasındaki rolü ise çalışmanın yöntemini oluşturmaktadır. 
Derrida'ya göre aslolan metindir. "Yapısöküm tekniği, gerçek mutlak bir doğru olmadığını özellikle Batı metafiziğinde kesin gibi görünen doğruları farklı açılardan bakarak eleştirmemizi istemektedir (Yanık, 2016, s.91)." Yapısökümün, Derrida tarafından da net olarak tanımlanamayan bu haliyle, bilimkurgu türü metinlerindeki değişimin ortaya çıkarılarak söylem üzerindeki etkilerin tespitini amaçlayan çalışmalara dayanak teşkil edebileceği düşünülebilir. "Yapısöküm, temel olarak metnin yapısal dokusunu parçalara ayırarak ele aldığı metin içerisindeki kavramlardan hareket eder (Güven ve Serarslan, 2018, s. 43).” Arrival filmindeki, doğu-bat1, uzayl1-dünyalı, doğrusal-doğrusal olmayan ve dost-düşman karşıtlıklarının yer değiştirmesi bilimkurgunun değişimine de 1 şı tutmaktadır. Ancak, filmde bilimkurgunun uylaşımları değişmemekte mevcut kavramlar ışığında yeni bir yaklaşım sergilenmektedir.

Sinema filminin ve bilimkurgu filminin bir metin olarak değerlendirilmesi mümkündür. Merriam'a göre; araştırma konusuyla ilgili raporlar, kitaplar, arşiv dosyaları, video ve ses kayıtları, görsel materyaller gibi belgeler de metin analizi yolu ile kullanışlı verilere dönüştürülebilir (aktaran Baltacı, 2019, s. 376). "Medya metinlerini inceleme türleri arasında yer alan metin çözümlemesi metni yorumlayarak anlamlandırır. Bu bağlamda, tüm niteliksel araştırmalar metin analizidir. Tüm bu analizler aynı zamanda metnin içeriğine baktıkları için hepsi de içerik analizidir" (Erdoğan, 2012, s. 149).

Bu çalışmada, Denis Villeneuve'ün 2016 yılı yapımı Arrival (Geliş) filmine metinsel boyutta Derrida'nın yapısökümcü yaklaşımıyla yapılacak tür analizi ile bilimkurgu türünün temalar ve içerikleri bağlamında tarihsel süreçteki değişiminin tespiti amaçlanmıştır. Türün değişiminin, temel özellikler, anlatı yapısı, sinematografi, temalar, ikonografik özellikler ve üretildikleri dönemdeki toplumsal beklentilerle ilişkilendirilerek analiz edilmesi hedeflenmiştir. Çalışmada, metnin örtük anlamının çözümlenmesinde, bilimkurgu türünün genel kabullerinin fillmde ne denli değişikliğe uğradığının tespiti için yapı-sökücülük bağlamında değerlendirmeler yapılacaktır. Analizde, Denis Villeneuve'ün bilimkurgu türüne auteur boyuttaki katkısı Arrival (Geliş) (2016) filmi bağlamında değerlendirilecektir.

\section{Bilimkurgu Türü}

Bilimkurgu, çoğu zaman referanslarını bugünün dünyasından alan bir tür olarak sinemanın ilk yıllarından itibaren varlığını sürdürmüştür. Nijat Özön'ün "Sinema Uygulayımı Sanatı Tarihi” isimli eserinde "önceleme filmi" olarak nitelediği bilimkurgu "bir yandan bilime dayanır, bir yandan kurmacaya yaratma gücüne" (Özön, 1985, s. 154). Bilimsel bir bakış açısı ya da bilimsel gerçeklerden hareket edilmesi, bilimsel gerçekliğin sergilendiği bir tür olduğu anlamına gelmez. "Kurgusal gerçekliğin inandırıcılığı açısından bilimsel bakış açısı bir anlatı öğesi olarak kullanılmaktadır. Bilimkurgu türünün tanımlanması aşamasında bilimsel verilere dayanılarak, ileriki yıllarda ortaya çıkaracakları gelişmelerin insanlar ve toplum üzerinde yapabileceği etkileri düsslemek ve kestirmek yoluyla gerçekleştirilen filmleri anlamak mümkündür" (Özön, 2008, s. 248). "Bilimkurguda izleyiciye sunulan gelecekte yaşanacak dünya betimlemesinde "bezem, donatım, makyaj, sinema hileleri önem kazanır" (Özön, 1985, s. 154).

Klasik anlatı ürünleri ve Hollywood film sektörünün ürünleri olarak bilimkurgu filmleri de diğer türler gibi temel birtakım çatışmalar üzerine kurgulanmaktadır. Wright'ın çatışma türleri bağlamında oluşturduğu dört temel tür sınıflamasına göre; "western, iyiyle kötü arasındaki çatışmanın şiddetli eylemle çözülmesine; korku, sorun çözmede akla dayananla, geleneksel inançlara dayanan yollar arasındaki çatışmaya; gangster, toplumsal ve bireysel başarı arzusuyla "öteki" olma arasındaki çatışmaya ve bilimkurgu, istilacılarla düzeni korumak isteyenler arasındaki çatışmaya dayanmaktadır" (Abisel, 1995, s. 51). Bilimkurgu türünün özellikle 1950'lerden itibaren ortak özelliklerinden bazıları; "bilimsel ve teknolojik ilerlemelerin getirileri ve sonuçları üzerinde düşünmek, uzay yolculuğu ve/veya uzaylılarla temas ve uzak gelecektir" (Buckland, 2018, s. 159).

Türler arasında geçişler olduğu tarihsel süreçte gözlenebilen bir durumdur. Sektörel tercihler ve izleyici taleplerine göre alınan ticari kararlar türdeki değişimi beraberinde getirmektedir. "Bilimkurgu 
türünün korku ve western türlerinin sözdizimsel özelliklerini kullandığı tür filmleri üzerine yapılan anlambilim ve sözdizimi temalı araştırmaların bir sonucudur" (Altman, 1984, s. 13). Bilimkurgu filmlerinde yüksek teknoloji kullanan ordular, yabancılar, robotlar ya da uzaylıların tehdit oluşturduğu sıradan insanların gündelik yaşantısı ve toplumsal düzendir. Kahramanlar, bozulan toplumsal düzeni yeniden sağlayarak geleneksel değerler ile ilgili farkındalığı sağlamakta diğer tür filmlerinde olduğu gibi toplumsal sistemin devamlılığı yanında yer almaktadır. Bilimkurgu filmlerinin, yüksek teknoloji, robotlar ve geleceğin dünyası temaları bağlamında günümüz dünyası ve toplumsal sistemine ilişkin mesajlar vermekte olduğunu söylemek mümkündür.

Bilimkurgu türü bilimsel gerçeklere dayalı ve pozitif bilimlerin yasalarının hükmettiği bir anlatıyı temel almamaktadır. "George Méliès, Gaston Velle, Max Fleischer'ın ilk kısa filmlerin çoğu, aya veya Mars'a yapılan gezilerin betimlemeleriydi. Bu filmlerdeki teknolojiler ve diğer gezegenler hakkında yapılan spekülasyonlar gerçek bilim, teknoloji ya da doğa yasalarıyla ilgili olmayan fantastik öğelerdi” (Calvin, 2014). Sinema, teknolojik bir yenilik olarak ortaya çıktığında, filmler ve onlarda kullanılan özel etkiler birer sihirbazlık gösterisi biçiminde algılanmıştır. Bilimkurgu türünün fantastik doğası ile birleştiğinde "sinemanın ilk yıllarındaki bilim-kurgu örnekleri, bilime karşı duyulan kentsoylu hayranlığı yansitan edebiyat ürünlerinden oluşturulmuştur. Örneğin, George Melies'in La Voyage dans la lune (Aya Seyahat) (1902), Jules Verne ile H. G. Wells'in romanlarından aktarılmıştır” (Onur, 2011, s. 67). On altı dakikalık Aya Seyahat filminde bir grup gökbilimcinin Ay’a yaptıkları keşif gezisi anlatılmaktaydı. "Filmin rengarenk dünyası daha çok dekor, kostüm ve makyajlara dayanıyor, gerçekleştirilen film hileleri bunlara daha da canlılık katıyordu" (Ünal, 2015, s. 118).

Melies, 1907 y1linda Jules Verne roman1 20000 Leagues Under the Sea'yi (Denizler Altında 20000 Fersah) sinemaya uyarlamıştır. "Romanın en iyi yorumu Amerikalı yönetmen Stuart Paton tarafından 1916 yılında filme alınmıştır. Su altı fotoğrafçılığının ilk örnekleri bu filmde verilmiştir. Film, özel efekt, dekor ve egzotik kostümleri ile dikkat çekmiş̧tir" (Çoker, 2016, s. 20). "1919 yılında İngiltere'de HG Wells'in The First Men in the Moon (Ayda İlk İnsanlar) isimli romanından aynı adla uyarlanan yönetmenliğini Bruce Gordon ve J.L.V. Leigh'in yaptığı film gerçekleştirilmiştir" (Acar, 2017, s. 380).

"Bilimkurgu türünün dünya ölçeğindeki ilk örneklerinden Rus yönetmen Yakov Protazonov'un yönettiği 1924 yapımı Aelita, Mars Kraliçesi isimli bilimkurgu filmi, Alexei Tolstoy'un Aelita isimli kitabından uyarlanmıştır. Film Mars gezegenindeki bir iş̧̧i devrimini konu almıştır" (Çoker, 2016, s. 26). 1927 yılına gelindiğinde Alman dışavurumcu sinemasının önemli yönetmenlerinden Fritz Lang'in bilimkurgu tarihi açısından en önemli eserlerinden birisi olan Metropolis filme alınmıştır. "Romanı ve senaryosu Thea von Harbou'ya ait olan film gelecekteki bir şehirde geçmektedir. Şehri yöneten ve planlayan kesim ile makinelerle yaşayan işçi sınıfının bir aşk hikâyesiyle yaklaştırılması konu alınmıştır" (IMDB, 2019c). "Film distopik özellikleri ve bütçesi ile Dönemin Almanyası hakkında önemli ipuçları vermektedir" (Çoker, 2016, s. 33).

1930'lu yıllar bilimkurgu sinemasında karamsar temaların hâkim olduğu bir dönemdir. "Birinci dünya savaşı sonrasında bilime duyulan şüphe ve Amerika Birleşik Devletleri'nde (ABD) 1929 ekonomik bunalımından kaynaklanan durum bilimkurguda kötümserliğin egemen olduğu temaları görünür k1lmıştı”" (Onur, 2011, s. 68). 1920'ler sonunda ve 1930'lu y1llarda Hollywood'da ilgi uyandıran bir diğer tür de müzikallerdir. Yapımcılar dünyanın çeşitli yerlerinden gelen müzikhol yıldızlarıyla filmler yapmışlardır. "Müzikal filmler radyo programlarını, sahne aşırılıklarını ve yönetmenliğini David Butler'ın yaptığı Just Imagine (Sadece Hayal Et) (1930) gibi filmlerde bilimkurgu örgülerini temel almışlardır" (Altman, 2008, s. 343). 1980 yılında geçen öykü New York ve Mars gezegeninde geçen bir aşk hikâyesidir. "Sadece Hayal Et filmi, uçakların otomobillerin yerini aldığı, insanların numaralarla isimlendirildiği, yemeğin yerini tabletlerin aldığı, evlilikleri devletin düzenlediği ve nesillerin tüp bebeklerle üretildiği bir bilimkurgu müzikaldir” (Reeves, 2019).

İkinci Dünya Savaşı öncesi dönem sinemanın propaganda amaçlı kullanımını gözlemlemek mümkündür. Yönetmenliğini Curtis Bernhardt'ın üstlendiği, 1933 yılı yapımı Der Tunnel (Tünel), 
Nazi Almanyası'nda çekilen ilk bilimkurgu filmidir. "Avrupa ve Amerika arasında yapımı on beş yıl sürecek bir tünel projesini anlatan filmde propaganda öğelerine yer verilmiştir" (Çoker, 2016, ss. 4849). Bilimkurgu filmleri ilgi uyandırdıklarında kahramanlarının yeni maceralara atıldığı seri filmler haline getirilmeleri 1930'lu yıllardan itibaren Hollywood'un başvurduğu ticari çözümler arasındadır. "Space-opera"ların en başarılısı Frederick Stephani'nin yönettiği Flash Gordon'dur (1936). Alex Raymond'un karikatüründen uyarlanan Flash Gordon, Mongo Gezegenindeki "şeytani” İmparator Ming ile mücadele etmektedir. Ming, oryantal tiranlık ve çöküş temalarıyla 1941 yılında savaşla sonuçlanacak ABD Japonya rekabetinin temsili olarak değerlendirilmektedir” (Roberts, 2006, s. 192).

Teknik düzeyde değerlendirildiğinde 1940'lı ve 1950'li yılların bilimkurgu filmlerinde maket canlandırma tekniklerinden faydalanıldığını söylemek mümkündür. Dikkat edilmesi gereken nokta izleyicilerin uygulanan yöntemlerin sonuçlarını hayret verici olarak algılamasıdır. "Oluşturulan gerçekliğin ihlal edilmesi bilimkurgu öyküsünü başlatır. Uzay, zaman gezginleri ve genetik mutasyonlar gerçekçi dünyanın ve bilimsel gerçekliklerin iyi tasvir edilmesi olmadan mümkün olmayacaktır. Bu durumu, bilimkurgunun gerçeklikle zorunlu bağ 1 olarak açıklamak mümkündür" (Sobchack, 2008, s. 363).

1950'li yıllar İkinci Dünya Savaşı'nın ardından bilimkurgu türünde üretimin arttı̆̆ bir dönemdir. İnsanlığın yaşadığı en yıkıcı savaşta nükleer teknolojinin savaş için kullanılmasının oluşturduğu korku ve savaşın bitmesinin soğuk savaş dönemini başlatması bilimkurgu türü için yeni alanlar açmıştır. "Dönemin sosyolojik ve psikolojik atmosferi bağlamında, "soğuk savaş komünizmi ve atom bombası filmlerinde başka gezegenlerden gelenler dünyayı ele geçirmek istemektedirler. Filmlerde görülen McCarthy Amerikasındaki komünizm korkusunun dışavurumu olarak açıklanmaktadır" (Onur, 2011, ss. 68-69).

Tüm yaşanan felaketlerin ardından ortaya çıkan kuşku 1950'li yılların bilimkurgusunu günümüz tehditlerine odaklamıştır. "1950'li yılların bilimkurgu filmleri genellikle gelecekte değil, günümüzde geçer, çünkü nükleer güçteki yeni bilimsel ve teknolojik ilerlemelerin getirileri ve sonuçları üzerinde dururlar. Getiriler ve sonuçlar her zaman olmasa bile çoğu zaman negatif değerlendirilir" (Buckland, 2018, ss. 159-160). Nükleer savaşlar, nükleer testlerin sonucunda ortaya çıkan yaratıklar dönemin filmlerinin temaları arasındadır.

1950'ler UFO'ların (unidentified flying object - tanımlanamayan uçan cisim) görüldüğü ve bunlara ilişkin filmlerin yapıldığı bir dönemdir. Çoğunlukla dünya dışı varlıkların işgal amaçlı ziyaretlerini anlatan filmler arasında daha farklı iletiler veren filmler de bulunmaktadır. Yönetmenliğini Robert Wise'ın yaptığı, The Day The Earth Stood Still (Dünyanın Durduğu Gün Uçan Dairelerin Esrarı) (1951), insansı uzaylı Klaatu ve gümüş renkli dev robotunun UFO'ları ile dünyayı ziyaretini anlatmaktadır. "Klaatu öldürüldüğünde tekrar hayata döner, dünyayı şiddete son vermeye çağırır. Aksi halde, insanlık yok olacaktır. Filmdeki yok olma ya da yok edilme tehdidini nükleer teknolojinin saldırgan olarak kullanılmasının yıkıcı sonuçları olabileceğine bir gönderme olarak düşünmek mümkündür" (Roberts, 2006, s. 220). Yönetmenliğini Don Siegel'ın yaptığı, The Invasion of The Body Snatchers (Merihten Saldıranlar) (1956) filminde küçük bir kasaba doktoru etrafındaki insanların duygusuz uzaylı kopyalarla değiştirildiğini fark etmektedir. "Kent yaşamındaki insanların yaşadığı yabancılaşma ya da otoritenin toplumu tek tipleştirme çabası olarak yorumlanmış bir filmdir, bilimkurgu türünün en önemli örneklerinden birisi olarak görülmektedir” (Çoker, 2016, s. 105).

1957 yılında kurgu ve belgeselin birleştirildiği bir örnek olan yönetmenliğini Pavel Klushantsev'in üstlendiği Doroga k Zvezdam (Yıldızlara Yolculuk) isimli bilimkurgu belgesel film yapılmıştır. "Film, Konstantin Tsiolkovsky'nin ilk roket deneylerinden insanlı ay uçuşuna kadar astronotiğin geçmişi ve geleceğini konu almıştır. Belgeselde, kurgusal olarak Ay'ın kolonileştirilmesi anlatılmıştır" (IMDb, 2019b).

Bilimkurgu filmleri arasında senaryosu ve üslubuyla dikkat çeken bir diğer yapım yönetmenliğini ve senaryo yazarlığını Jean-Luc Godard'ın yaptığı Alphaville'dir (1965). "Hem 
üsluplu bir bilimkurgu macerası hem de birbiriyle çekişen, insani aşk ve yeni teknoloji iddialarıyla ilgili bir toplumsal mittir. Filmin konusu gelecekte geçmektedir" (Nowell-Smith, 2008, s. 854). 1950'lilerde kara film niteliğindeki yapımlar ve nükleer savaş korkusu temelinde ilerleyen bilimkurgu türü 1960'lı yıllarda uzaylı istilası gibi temaları devam ettirmiştir. Politik temelli filmler, distopyalar ve space-opera türündeki yapımlar bilimkurgu türünün bu dönemindeki diğer temalarını oluşturmuştur.

1968 yapımı Stanley Kubrick filmi, 2001: A Space Odyssey (Uzay Yolu Macerası) bilimkurgu türünde çığır açan bir yapımdır. Senaryosunu Stanley Cubrick ve Arthur C. Clark'ın yazdığı filmdeki, "epik yolculuklar bir Avrupa sanat filmi kadar yavaş ilerler ve aşırı titiz görüntüler, ekrandaki karakterler pencerelerden dışarı bakmakta nadiren sorun yaşasalar bile izleyiciyi bunaltır. Öykü en az düzeydedir ve muğlaktır" (Newman, 2014, s. 292). Filmdeki en önemli çatışmalardan bir tanesi yabancı kültürlerle temasa geçmek için uzayda seyahat eden geminin bilgisayarı HAL'ın gemi mürettebatını engellemek amacıyla onları öldürmeye çalışmasıdır. İnsanlığın oluşturduğu teknolojinin kendisini tehdit etmesi filmde işlenmiştir.

Yönetmen George Lucas'ın Star Wars (Yıldız Savaşları) (1977) filmi, Flash Gordon serisinin etkisinde ortaya çıkan epik bilimkurgu serisinin ilk yapımıdır. "Film yalnızca bilimkurgu türü adına değil tüm Hollywood film endüstrisi adına ticari bir başarı öyküsüdür. Stüdyosuna yüz milyonlarca dolar kazandıran yapım yeni bir dönem başlatmıştır" (Gomery, 2008, s. 538). Farklı uzay uygarlıklarının mücadelesini anlatan Yıldız Savaşları ile aynı dönemde Ridley Scott, Alien (Yaratık) (1979) filmini yönetmiştir. Alien filminde bir yaratığın, uzay gemisi içerisindeki mürettebatı tehdit etmesi konu alınmıştır. Sonraki dönemde, Prometheus (2012) gibi devam filmleriyle sürecek seride Ridley Scott insanlığın ortaya çıkışında dünya dışı akıllı uygarlıkların etkisinden bahsetmektedir. Ancak, filmde insansı robotlar, insan ve ölümsüzlük gibi temalar üzerinde yorumlar da yapılmaktadır.

E.T. (Extra - Terrestrial) (1982), televizyon kökenli yönetmen Steven Spielberg'in muhafazakâr aile yaşantısı ile uzaylı yaratık figürünü buluşturduğu ticari bir başarıdır. Yapım ikonik sahneleriyle bu kez dost bir uzaylı ile bir grup çocuğun macerasını konu almaktadır. E.T.'de dünyalılar uzaylı yaratık için tehdittir. Yönetmen George Miller'ın Mad Max (Çılgıı Maks) (1979) filmi devamı da çekilen Avustralya yapımı bir distopyadır. Nükleer savaşla yok olmuş medeniyetten arta kalanlar üzerinde yaşamaya çalışan insanların öyküsü anlatılmaktadır. Eşi otoyol çeteleri tarafından öldürülen polis memuru Max'in intikam öyküsü, Avustralya çölleri ve otoyol fonunda işlenmektedir.

Blade Runner (Ölüm Takibi) (1982) filmi, Ridley Scott yönetmenliğinde başlayan ve Blade Runner 2049 ile Denis Villeneuve yönetiminde devam eden iki filmlik bir distopyadır. Blade Runner, insan olmak ne demektir? Sorusu çerçevesinde ilerlemektedir. Kimlik sorusu bu bağlamda ele alınmaktadır. "İnsani değerler ve hafizanın temelde insanı insan yapan değerler olduğu, insan replika karşıtlığ 1 ile anlatılmaktadır. Bilimkurgu, kara film, gerilim, western ve aşk filmi hibriti olarak Blade Runner, görsel biçem olarak da eklektik bir yapıya sahiptir" (Gianetti, 2001, s. 323). Harvey’e göre; "filmde neoliberal yapının sebep olduğu sanayisizleşme sonrası çöküş işlenmektedir" (aktaran Bould, 2015, s. 192).

James Cameron'ın yönettiği Terminator I ve II filmlerinde (Yokedici I-II) (1984-1991) robotlar dünyayı ele geçirmiştir. Bu distopik evrende insan temel tehdit olarak algılanmış ve yok edilmeye başlanmıştr. Zaman yolculuğu, robot-insan mücadelesi Teminator serisinin ana konusudur. Fiziksel güç film serisindeki gösterenlerden en önemlilerindendir. Ancak, "bu filmlerin kahramanlarının müthiş kaslı vücutları, onları gördükleri cezanın büyüklük ve acımasızlığından koruyamamaktadır" (Sartelle, 2008, s. 592).

Michael Bay'in yönettiği Armageddon (1998) filmi, uzaydan gelen tehdit temalıdır. Bu kez tüm dünya birleşerek yeryüzüne çarparak hayatı bitirecek bir meteoru yok etmek için çalışmaktadır. Film, herhangibir yabancı kültürü tehdit olarak algılamakta, yüksek teknoloji ve dayanışma ile doğanın oluşturduğu tehdidin önlenmesi temasını işlemektedir. Lana ve Lilly Wachowski kardeşlerin yönettiği Matrix (1999), felsefi yönü ve yenilikçi efektleriyle önemli bir bilimkurgu serisinin ilk filmidir. 
İnsanların makinelere güç sağlamak için tarlalarda yetiştirildiği bu distopyada Neo, insanlığ1 kurtaracak mesih rolündedir. Filmde, gerçeklik ve hayat kavramlarına ilişkin yorumlar aksiyon sahneleriyle desteklenmektedir.

Yönetmenliğini James Cameron'un yaptığı Avatar (2009), gelişmiş toplumların, gelişmemiş toplumlar üzerindeki baskısının bir alegorisidir. Bilimkurguya özel anlatı yapısı içerisinde yüksek teknolojiye sahip bir ordu doğal kaynaklarını ele geçirmek için uzaydaki daha az gelişmiş bir uygarlığın topraklarını işgal etmektedir. Inception (Başlangıç) (2010) ve Interstellar (Yıldızlararası) (2014) filmleri, yönetmen Christopher Nolan'ın kendine özgü biçemini ortaya koyduğu yapımlardır. Klasik anlatı sinemasının kalıplarını kullanan Nolan, zaman olgusunu nedensellikle yorumladığı kurgu anlayışıyla bilinen anlatı yöntemlerini kullanarak izleyiciyi hayrete düşüren filmler ortaya koymuştur.

Bilimkurgu tarihinde öne çıkan filmler, uzaylı istilacı, nükleer tehdit, uzaylı canavar, alternatif zaman-uzam, post-apokaliptik ve distopik evrenler gibi temalarla üretilmiştir. Yabancı kültürlerle ilgili tehdit algısı, siyasi ve kültürel rekabet, gerçeklik, kimlik, insanlığın zayıf kültürler üzerine tahakkümü ve kültürel hoşgörü gibi olguları sorgulayan yapımlar olduğunu söylemek mümkündür. Sözkonusu yapımların üretim tercihlerinin dünyada ve filmlerin üretildiği topraklardaki sosyolojik, kültürel ve ekonomik durumla bağlantılı olarak değişiklik gösterdiğini söylemek mümkündür.

\section{Bir Bilimkurgu Filmi Olarak Arrival}

Bilimkurgu türünde film üretimi 2010'lu yılların sonunda da devam etmiş̧ir. Tür filminin bir özelliği olarak bilimkurgu da diğer türlerle etkileşim haline geçmiştir. Dram, gizem ve aksiyon bu türler arasındadır.

\section{Denis Villeneuve ve Sinema Anlayışı}

Bilimkurgu türünün diğer türlerle etkileşim haline girmesiyle ele aldığı konular arasında bağlantı kurmak mümkündür. Denis Villeneuve'ün yönettiği Arrival (Geliş) (2016) ve Blade Runner 2049 (Bıçak Sırtı) (2017) filmleri bu kapsamda değerlendirilebilir. Uzaylılar ve genetik kopyalar, bilimkurguda dost, düşman ve tehdit olmak dışında insan olmak, kimlik, kültür ve hafiza kavramlarının ele alınması için kullanıldığında tür, gizem ve dramla etkileşime girmiştir.

"Yönetmen ve senarist Denis Vileneuve 3 Ekim 1967 tarihinde Kanada'da doğmuştur. Kariyerine National Filmboard of Canada'da (Kanada Ulusal Film Kurulu) yönetmen olarak başlamıştır" (Morningbell, 2019). Villeneuve'ün özgün ve rahatsız edici atmosferi olan filmleri genellikle travma, kimlik ve hafiza temalarına odaklanmaktadır. Yönetmenin, bilimkurgu türünü psikolojik atmosfer ve dramatik altyapı bağlamında diğer türlerle etkileşim haline soktuğunu ve derinleştirdiğini söylemek mümkündür. "Yönetmeni ilk etkileyen film Star Wars (Yıldız Savaşları), ilk etkileyen yönetmenler Ingmar Bergman ve Stanley Kubrick olmuştur. Villeneuve, yükseköğrenimini fen bilimleri ve iletişim alanlarında almıştır" (Fontaine ve Mullen, 2017). Bu bağlamda, Villeneuve'ün filmlerinde görülen türler arası etkileşimin ve çok boyutluluğun izleri eğitim hayatında görülmektedir. Filmlerinde kimlik ve hafıza gibi sosyoloji ve psikoloji alanlarıyla ilgili temaları seçiminde iletişim eğitimi almasının etkili olduğu sonucuna varmak mümkündür.

"Yönetmen, 1990 ve 1991'de Radio - Canada'nın La Course Europe-Asie genç film yarışmasını kazanmıştır" (Beyazperde). İlk uzun metrajlı filmi Un 32 août sur terre'dir (32 Ağustos Dünya) (1998). "Konusu, Simone'un hayatını değiştiren bir trafik kazasından sonra çocuk sahibi olmak için arkadaşı Philipe ile Salt Lake Çölü’ne yaptığı yolculuktur” (IMDb, 2019d). Villeneuve, filminde Simone karakterinin değişiminde yaşadığı travmanın etkisini vurgulayarak psikolojik düzeydeki bir etkiyi vurgulamıştır.

Prisoners (Tutsak) (2013), bir dedektif iki kız çocuğunun kaybolması olayını soruştururken çocuklardan birinin babasının kendi soruşturmasını sürdürmeye çalışmasını anlatmaktadır. "Prisoners 
filminin en önemli özelliği Villeneuve'ün filmlerinin ayırt edici özelliği haline gelen karmaşık psikoloji ve karanlık estetiktir" (Fontaine ve Mullen, 2017). Filmin görüntü yönetmeni Roger Daekins en iyi sinematografi dalında Oscar adayı olmuştur. Prisoners filmi acının ve travmanın sıradan bireyleri değiştirmesini ve şiddetle ilgili ahlaki kabullerini yeniden sorgulamalarına sebep oluşunu kendi yapısı içersinde ortaya koymuştur. Bunun yanında, ahlaki kabullerin değişiminin toplumsal yapı içersinde bireysel özgürlüklerin alanını yeniden biçimlendirdiği vurgusu yapılmıştır.

Incendies (İçimdeki Yangın) (2010), Enemy (Düşman) (2013) ve Sicario (2015) gibi filmleriyle tanınan Villeneuve'ün Oscar, Cannes, British Academy of Film and Television Arts (BAFTA), Venedik gibi ödül adaylıkları bulunmaktadır. Villeneuve'ün 1982 yılı yapımı Blade Runner'ın (Ölüm Takibi) devamı niteliğindeki Blade Runner 2049 (Bıçak Sırtı) (2017) ve Arrival (Geliş) (2016) filmleri insan olmanın neliği, farklı kültürlerle iletişime geçilmesindeki kültürel dinamikler ve hafiza gibi kavramları ele almıştır. Blade Runner 2049 (Bıçak Sırtı) (2017) filminin görüntü yönetmeni Villeneuve'ün diğer projelerinde de birlikte çalıştığı Roger Daekins'tir ve en iyi sinematografi dalında Oscar ödülü kazanmıştır. Blade Runner 2049, kimlik ve hafiza kavramları ile ilgili olarak Villeneuve'ün yorumunu içermesi yanında; serinin özgün atmosferini de teknolojik gelişmeler sinematografi bağlamında yenileyerek sürdürmüştür. "Film, en iyi görsel efekt dalında da Oscar ödülü kazanmıştır. Blade Runner 2049, BAFTA ödüllerinde en iyi sinematografi ve en iyi görsel efekt ödüllerini (John Nelson, Paul Lambert, Richard R. Hoover, Gerd Nefzer) almıştır” (IMDb, 2019a). Film insan olmak ne demektir? Sorusuna cevap ararken toplumsal düzen ve kabullerin ahlaki temelleri üzerine bir dizi sorgulamaya da yer vermektedir.

Arrival (Geliş) (2016), Villeneuve'ün gizemli dramatik bilimkurgu anlayışının bir örneği olarak, uzaylı kavramı ve bilimkurgu türünün ikonografisi açısından özgün nitelikte bir yorum getirmesiyle bu araştırmaya konu edilmiştir. Film en iyi ses kurgusu dalında Oscar ödülüne layık görülmüştür.

\section{Arrival Filminin Tür Analizi}

Sinema sanatı açısından değerlendirilecek olursa, Arrival (Geliş) (2016) filminin bilimkurgu türüne özgü uylaşımlar ışığında değerlendirilmesi mümkündür. Ancak, film alışılagelmiş bilimkurgu anlatısı öğelerini; doğu-batı, uzaylı-dünyalı ve doğrusal-doğrusal olmayan karşıtlıkları bağlamında değiştirmektedir. Filmin çözümlemesinde, zaman ve uzaydan gelen varlık fenomenlerine ilişkin yorumlar Derrida'nın kalıplaşmış bakış açılarına karşı duran yaklaşımı açısından ele alınmıştır.

"Arrival filmi, Ted Chiang'ın "Story of Your Life" isimli öyküsünden, Eric Heisserer tarafından sinemaya uyarlanmıştır" (Fontaine ve Mullen, 2017). Bir dilbilimci olan Louise Banks'in (Amy Adams) dünya üzerine inen on iki uzay gemisinden birisinde bulunan dünya dişı yaşam formlarıyla iletişim kurmak üzere Amerikan ordusu tarafından fizikçi Ian Donnely (Jeremy Renner) ile birlikte görevlendirilmesini anlatmaktadır.

Film, klasik anlatı yapısındaki diğer örneklerde olduğu gibi başlangıç bölümünde teması hakkında bilgi vermektedir. İzleyiciye sunulan kesitler aracılığıyla Louis'in kızıyla bebekliğinden itibaren olan bağı ve onu erken yaşta kanserden kaybedişi anlatılmaktadır. Bu bölümde, Louis'in evli olduğu vurgusu parmağındaki yüzük detayıyla izleyiciye verilmektedir. Babaya ilişkin bilgi sunulmamaktadır.

Flashback sekansında Louis'in sesinden nondiegetik olarak; "Hafiza garip bir şey... Benim sandığım şekilde çalışmıyor... Zamana çok bağımlıyız... Sıralı düzenine...” sözleri duyulmaktadır.

Denis Villeneuve'ün filmlerinin genelinde olduğu gibi hafıza temasına vurgu yapılacağı bilgisi izleyiciye verilmektedir. Ayrıca, Louis'in kızını kaybetmesinden kaynaklanan travması anlatılmaktadır. İnsanın hafızasının zamanın kronolojik sırasına bağımlı olduğu vurgusu da filmin geneli için önemli bir dügümü ortaya koymaktadır. Louis bebeği ağladığında, "bana geri gel." cümlesini kurar. Kızını kaybettiğinde de ona seslenirken, "bana geri gel." der. İki önemli anda da aynı cümlelerin kurulması dil ve ifadenin boyutlarının film açısından önemini ortaya koymaktadır. 
Yönetmen, filmin genelinde hafiza ve önemli dönüm noktalarının hayata etkisini dil bağlamında ele alacağını, anlamı boyut değiştiren cümleler vurgusuyla anlatmaktadır. Doğrusal-doğrusal olmayan karşıtlığının işlendiği bu bölümde, insanların sahip olduğu krolojik bakış açısının metinsel düzeyde değiştirildiğini görmek mümkündür.

Louis dış sesle devam eder; "Ama artık başlangıçlara ve sonlara inanmıyorum... Hayatınızın ötesindeki hikayenizi belirleyen günler vardır. Geldikleri gün gibi..." Açıkça başlangıç ve sonlara dayalı kronolojik bir zaman ve hafiza anlayışına inanılmadığı yargısı izleyiciye sunulmaktadır. Önemli anlar ve günler vurgusu yapılmaktadır. Dünya dışı varlıkların gelişi için "onlar" zamiri kullanılmaktadır. Onlar, sözcüğ̈̈ "biz" ve "diğerleri” ya da "ötekiler" anlamındaki ifade biçimiyle dünya dışı varlıkların istilasını konu alan bilimkurgu filmlerinin söylemiyle aynı düzlemdedir.

Arrival (Geliş) (2016) fillminin başlangıç bölümünde, öykünün temasına değinilirken filmin kavramsal temelleri yanında protagonist de tanıtılmaktadır. Louis, çocuğunu kaybetmiş bir annedir. $\mathrm{Bu}$ önemli travma onun hayata ve hafızaya ilişkin yargılarını değiştirmiştir. Filmde, Villeneuve'ün yapımlarının bir karakteristiği olarak karanlık, durağan ve belirsiz bir atmosfer hakimdir. Üniversiteye giriş ve ders yapılacak sınıf karanlıktır. Louis dersine giriş yapar. Öğrencilerinin dikkati derste değildir. Bilgisayarlardan ve telefonlardan gelen sesler dersi bölmektedir. Öğrenciler, Louis'den televizyonda bir haber kanalı açmasını isterler. Louis'in bel plan reaksiyon çekimindeki ifadesi durumdan haberdar olmayan tek kişinin kendisi olduğunu gösterir nitelikte ve tedirgindir. Psikolojik anlamda gergin bir hava hakimdir. Amerika'nın ve dünyanın farklı yerlerine on iki uzay gemisi inmiştir. Ancak, bu filmin antagonistinin sunumu değildir. Uzaylıların dost ya da düşman olup olmadıkları belirsizdir. Yeryüzündeki insanlar tedirgindir. Sınıfta acil durum alarmı çalar. Filmdeki gergin ve belirsiz atmosfer sessizlik içerisindeki alarmla akustik olarak vurgulanmıştır.

Üniversite kampüsündeki kapalı hava yönetmenin filmdeki genel karanlık atmosferiyle uyumludur. Kampüste tedirgin bir ruh hali hakimdir. Ancak, kargaşanın hâkim olduğu bir dünya yerine kaza yapan araçlar ve gökyüzünde uçan uçakların sinyalini verdiği bir rahatsızlık vurgusu yapılmaktadır. Güney Amerika ve Ortadoğu gibi dünyanın diğer yerlerinde ise tedirginlik kargaşaya dönüşmüştür. Radyoda yapılan yorumda uzaylıların ziyareti dostane ise neden bir yerine on iki gemiyle yapıldığı sorusu sorulmaktadır. Klasik anlatı sinemasının bilgilendirme yöntemleri televizyon aracılığıyla devam etmektedir. Gemilerin yaklaşık dört yüz elli metre yüksekliğine oldukları anlatılmaktadır. Grafik bir gösterge olarak dünya haritası üzerinde gemilerin indiği bölgelere ilişkin bilgi de izleyiciye sunulmaktadır.

Film ikonografik olarak yerleşik anlatı sineması kabullerini kullanmak yanında farklı yorumları da barındırmaktadır. Haber bültenlerinde Rusya sınırlarındaki iki uzay gemisi ile ilgili olarak ordunun önlem aldığı anlatılırken Rus tankları gösterilmektedir. Amerika'da gerilim ise jet uçaklarının uçuşlarıyla anlatılmaktadır. Arrival'ın ilerleyen bölümlerinde izleyiciye sunulacak olan uzay gemisi ise bilimkurgu filmlerindeki uzay gemilerinin ortak görsel özellikleri dışındadır. Geminin tasarımı dikeydir. Metinsel karşıtlıkların Derrida'nın yaklaşımı açısından çözümlenmesinde ikonografik düzeydeki bir diğer karşıtlık da geminin tasarımıdır. Yeryüzüne inmek için tasarlanmış iniş takımları bulunmamaktadır. Bu özellik diğer bilimkurgu filmlerindeki gemilerle çelişmese de yeryüzüne temas etmeden havada asılı olarak beklemesi alış1lagelmiş bilimkurgu biçimselliği dışındadır. Havadadır ancak iniş yapmışçasına yeryüzüne yakındır.

Bilimkurgu filmi tür sinemasının bir özelliği olarak, aynı türdeki diğer yapımların uylaşımlarını kullanmaktadır. Böylece, izleyicinin ne izleyeceğini tahmin etmesini ve filmin anlaşılmasını sağlayarak ticari hedeflerine ulaşmaktadır. Arrival, afiş tasarımı ile bir bilimkurgu filmi olduğu izlenimini vermektedir. Başlangıç bölümü, genel atmosferi ve ikonografi ise alışılagelmiş bir uzaylı temalı bilimkurgu olmadığını göstermektedir.

Filmin protagonisti Louis, klasik bilimkurgu filmine özgü niteliklerin dışındadır. Bilimkurgu filmi kahramanı olarak kadının, erkek kahramanın yardımcısı ya da erkeksi güce ve çevikliğe sahip olarak temsil edilmesi türe özgü yaygın bir kabüldür. Edebiyatta olduğu gibi, sinema alanında da kadın 
temsillerinin değişikliğe uğradığını söylemek mümkündür. Bu değişimde, edebî türlerde kadının ele alınış şeklini ve kadına karşı yaklaşımı ortaya çıkarmak amacıyla başlayan ve kısa sürede kadına yönelik başka sorunlara da dikkat çekmeyi başaran feminist yaklaşımın etkilerini olduğunu söylemek mümkündür (Karadeniz, 2019, s. 284). Arrival filmindeki Louis karakteri, bilimkurgu türündeki alışlagelmiş kadın kahraman kabullerini yıkmaktadır. Film boyunca karşısında yenmesi gereken bir düşman bulunmamaktadır. Çözülmesi gereken bir gizem bulunmaktadır. Ordunun kendisinden beklediği, uzaylı ziyaretçilerin ne yapmak istediğini bulmak için onlarla iletişime geçmelidir. Bilimkurgu kahramanı anlatının bir özelliği olarak kısıtlı zaman içerisinde dünyayı ve sevdiklerini kurtarmak durumundadır. Louis annesinden uzaktadır, eşi ile ilgili bir bilgi verilmemektedir, ailesi ya da çocuğu bulunmamaktadır. Bilimsel merakı dışında kendisiyle ilgili bir motivasyon sunulmamaktadır. Bilimkurgu filmlerindeki kadın kahramanların, aksiyon filmlerinin gerektirdiği fiziki mücadele, çeviklik ve bilimsel zekâ ile erkek kahramanlarla aynı özellikleri gösterdiklerini söylemek mümkündür. Arrival filmindeki Louis karakteri, bir gizemi çözmeye çalışan, zeki ve sakin bir bilim insanı portresi çizmektedir. Mesleki anlamda kendine güvenlidir. Fizikçi Ian Donnely de aynı gizemi çözmek için görevlendirilmiştir. Onun da erkek kahramanlardan beklenen fiziki güç ve çeviklik gibi özellikleri göstermediğini söylemek mümkündür. Uzay gemisinde koruyucu kıyafetleri çıkaran ilk kişi de Louis'dir. Louis uzay gemisinde kendisini tanıtırken yazı tahtasına "insan" yazmıştır. İnsan türündeki farkılıkları anlatmak için kadın ya da erkek gibi kelimeler kullanmamıştır. $\mathrm{Bu}$ anlamda, bilimkurgu türünün bir kabulünün de yıkıldığını söylemek mümkündür.

Arrival filminde en büyük çatışmaların fikir düzeyinde yaşandığını söylemek mümkündür. Louis medeniyetin temelinin dil olduğunu savunmaktadır. Ian'a göre medeniyet bilim sayesinde varolmuştur. Film boyunca kurulan bir diğer kavramsal ilişki ise "dil" ve "savaş" kavramları arasındadır. Louis'in çalışmasında geçen "dil, bir çatışmada çekilen silahtır." Cümlesi Ian tarafından okunur. "Conflict" kelimesinin karşılığı olarak kullanılan 'çatışma' yanında, sözcüğün bir diğer karşılığ 1 da "fikir ayrılığı"dır. Denis Villeneuve, iletişim öğrenimi görmüş bir yönetmendir. İletişimin en genel tanımlarından birisi de kaynakla hedef arasındaki uyumlanma süreci olduğu yönündedir. Savaş da iletişim ve diplomasi yoluyla ulaşılamayan hedeflere ulaşmak için kullanılan yöntemlerdendir.

Filminde savaş ve iletişim süreçlerinin birer araç olarak sunulduğunu söylemek mümkündür. Savaş sorunu fiziksel olarak ortadan kaldırmaya yönelik güç kullanma, iletişim süreci ise uyumlanma ve anlaşmadır. Dil ve çatışma arasında kullanılan silah bağlantısının kurulmasının nedeni ise amaca ulaşmak için kullanılan araçlar olmalarıdır. Louis, uzay gemisinde ziyaretçilerle yaptığı görüşmelerde zamanı onlar gibi dairesel algılamaya başlamıştır. Filmin başından itibaren flashbackerle gördükleri aslında gelecekte yaşayacaklarıdır. İnsanlığın çizgisel ve kronolojiye dayalı algısının aksine uzaylılar zamanı dairesel bir süreç olarak algılamaktadır.

Uzay gemisinin içi de bilimkurgu ikonografisi dışında bir yapıya sahiptir. Uzaylı teknolojisini yansıtan araç gereçler yerine tünel yapılar bulunmaktadır. Renkli işıklar ya da bilgisayarlardan oluşan bir dekor bulunmamaktadır. Geminin kendi yerçekimi olması bilimkurguda işlenen bir uylaşımdır. Ancak, uzaylıların bulunduğu alana girişteki çekimde Amerikalı ekip tavanda görünmektedir. $\mathrm{Bu}$ çekimin, gemiye biniş anından itibaren işlenen yerçekiminin yönsel olarak farklı olduğu görselleştirmesi dışında metafor düzeyinde iletişime, varoluşa ve zamana ilişkin tüm kabullerin yer değiştirdiği biçiminde yorumlanması mümkündür.

Uzaylılar biçim olarak yedi bacaklı ve ahtapota benzer canlılardır. Kendilerine heptapod adı verilir. İfadesinden bir anlam çıkarılabilecek yüzleri bulunmamaktadır. Klasik anlatının duygu aktarımı aracı olarak yüz ifadelerini kullanma yaklaşımının yüzü olmayan heptapodlarla iletişime geçilmesi aşamasında Derrida'nın bakış açısı bağlamında yıkıldığını söylemek mümkündür. $\mathrm{Bu}$ durum, filmde heptapodlara ilişkin uyandırılan gizemin bir parçasıdır. Filmin son bölümünde Louis yanlarına girdiğinde heptapodlar bütün olarak görülebilecektir. Heptapodlarla iletişim kurmaya çalışan tek grup Amerikan ekibi değildir. Gemilerin iniş yaptığı Rusya, Çin, Venezuela ve Pakistan gibi ülkelerden ekipler de aynı konuda çalışmaktadır. Filmde gemilerin iniş yaptığı ülkelere ilişkin hiçbir 
bağlantı bulunamadığı söylense de harita konumlarından varılabilecek sonucu gelişmiş ve gelişmekte olan ülkeler olarak yorumlamak mümkündür.

Çin ekibi heptapodların kendilerine silah önerdiği ve dünyayı bir çatışmaya sürüklemeye çalıştıkları sonucuna varır. Filmde, doğu-batı karşıtlığının uzlaşmacı batı ve savaşçı doğu ekseninde geliştirdiğini gözlemlemek mümkündür. Çin ekibi, diğer ekiplerle teması keser ve savaşa hazırlanır. Bunun üzerine takipçisi olan ülkeler de aynı yönde karar alır. Bu aşamada, Amerikan ekibi de uzay gemilerinden uzaklaşmak durumunda kalır. Bir grup asker gemiye bomba yerleştirir. Yaşanan olay temel düzeyde insanların şiddete olan eğiliminin belirsiz durumlarda farklı kültürlerde aynı biçimde sonuçlandığını göstermektedir.

Louis, heptapodların önerdiği silahın, insanlığa zamanı onlar gibi algılama olanağı verecek dilleri olduğunu anlar. Heptapodlar, üç bin yıl içerisinde insanlardan yardım göreceklerini; bu nedenle, onlara kendilerini anlayacak ve aralarında birlik olmalarını sağlayacak bilgiyi vermeleri gerektiğini görmüşlerdir. Dünyanın on iki yerine inen gemilerin her biri mesajın bir bölümünü taşımaktadır. İnsanlık ancak birlik olursa bu mesajı çözebilecektir.

Louis, kendisine verilen emirleri dinlemez ve General Şeng'e ulaşır. Onu ikna etmek için eşinin savaşın kahraman değil dul ve yetimler ortaya çıkaracağına yönelik son sözlerini anlatır. General Şeng kendi üslerini dinlemez ve savaştan vazgeçer. On iki ülke heptapodların mesajını çözmek için birlikte çalışır. Louis dillerini öğretmeye başlar. Ian ile çocuklarının sonuçta öleceğini bilerek evlenir. $\mathrm{Bu}$ gerçeği bilerek yine de kendisiyle evlendiğini söylediğinde Ian ile evlilikleri biter.

Bilimkurgu filmlerinin güncel sosyolojik ve politik olaylar ile ilgili mesajlar verdiğini söylemek mümkündür. Soğuk savaş, terör ve hoşgörü temalı bilimkurgu filmleri üretilmiştir. Arrival filminde de az gelişmiş ülkelerle gelişmiş batı ülkelerinin birlikte çalışarak ve diyalog kurarak çatışmak yerine çözüm üretebilecekleri; böylece, ortak bir medeniyet inşa edilebileceği vurgusu yapıldığını söylemek mümkündür. Dünya eskisi gibi değildir, tıpkı filmdeki zaman, mekân algısı ya da gemiler gibi herşey alt üst olmuştur ve yeniden tanımlanmaktadır. Bu dönemde, farklı bakış açılarının ve algıların iletişimle anlaşılması gerekmektedir.

\section{Sonuç, Tartışma ve Öneriler}

Bilimkurgu türü, yüksek teknoloji, dünya dış1 canlılar, klonlar ya da robotlar ile izleyici kitlesinin dikkatini çekmekte ve dünyanın mevcut sosyolojik, kültürel durumu ile ilgili mesajlar verebilmektedir. Tür sineması, kültür endüstrisinin bir parçası olarak değerlendirilebilir. İzleyicisine rahatlıkla ulaşabilmek için filmlerin ayırt edilmesini sağlayacak bir dizi uylaşımdan yararlanmaktadır. Ayrıca, farklı türlerle etkileşim haline girebilmektedir.

Yönetmenliğini Denis Villeneuve'ün yaptığı Arrival (Geliş) (2016) filmi gizem, dram ve bilimkurgu türündeki bir yapımdır. Villeneuve, filminde karanlık ve durağan bir atmosfer oluşturmuştur. Filmin ana karakteri Louis Banks, geçmişinde çocuğunu kaybetmiştir. Bu travmanın ardından hayata ve hafizaya ilişkin yargıları değişmiş̧tir. Villeneuve'ün, filmlerinde yoğunlaştığı travma ve hafiza temalarını Arrival'da da sürdürdüğünü söylemek mümkündür.

Filmde, uzaylılar istilacı ya da gündelik hayattaki dostlar olarak konumlandırılmamıştır. Uzaylılar ile insanlık arasında çözülmesi gereken bir gizem mevcuttur. Bu gizem fiziki bir mücadele ya da savaş ile değil iletişim süreçleriyle çözülmektedir. Louis, meraklı bir bilim insanı olarak bu bilmeceyi çözmektedir. İnsan olması kendisinin tek kimliğidir. Filmde, zaman ve kronolojiyle ilgili tema kurgu bağlamında değil, klasik anlatı içerisinde mesaj iletebilmek adına kullanmıştır. $\mathrm{Bu}$ bağlamda, yapım klasik anlatı sineması kalıpları içerisindedir.

Filmde, uzaydan gelen heptapodlar insanlığı birleştirecek bir bilmece ile üç bin y1l sonra kendilerine yardım etmeye hazırlamak için dillerini öğretmeye çalışmaktadır. Güncel sosyolojik ve kültürel göndermeler yaptığı düşünülebilecek filmde, gelişmiş ve az gelişmiş ülkeler arasında yarını 
inşa edebilmek için işbirliği yapılmasının önemine vurgu yapılmaktadır. Dünya değişmektedir ve savaşmak yerine iletişime geçmek amaç olmalıdır.

Denis Villeneuve, Arrival filminde gizeme dayalı, bilimkurgu öğelerini kapsayan biçemini sürdürmüştür. Bireysel travmalara, kimlik ve hafiza olgularına yer veren bir yönetmen olarak Villeneuve, Arrival'da da çocuğunu kaybetmiş bir anne figürüne, onun hayata ve hafizaya ilişkin değişen görüşlerine yer vermiştir. Villeneuve'ün, soğuk savaş, terör ve hoşgörü temalı bilimkurgu filmleri dışında küresel işbirliğini ve farklı kültürler arasında iletişim kurmayı öneren bir yapıma imza attığını söylemek mümkündür.

Derrida'nın yapısökümcü analiz yöntemi ışığında filmde, doğu-batı, uzaylı-dünyalı ve doğrusal doğrusal olmayan karşıtlıkları ile bilimkurgu türünde biçimsel ve içerik düzeyinde değişiklikler yapıldığı görülmektedir. Arrival filminde, doğunun geri kalmış ve büyük güçlerin söylemlerine uyan biçimde tasvir edilmesi yerine; teknolojik olarak ilerlemiş ve bat1 ile eşit düzeyde müzakere eden düzeyde sergilendiğini görmek mümkündür. Ancak, batı müzakereci ve barışçı olarak yansıtılırken doğu savaşmaya daha istekli olarak sunulmuştur. Batı, doğu ile işbirliği yaparak iletişim ile sorunları çözmüştür.

Uzaylılar ise belirli bir tarafla dost ya da düşman değildir. İletişim aracılığıyla tüm uygarlıklara geleceğe ilişkin ipuçları vermeye çalışmaktadır. Bilimkurgunun yaygın tür özelliğine karşın dostluk ya da düşmanlık yerini farklı bakış açıları sunulmasına bırakmıştır.

Uzaylıların dili ve öyküde zamanın ele alınışı da doğrusal-doğrusal olmayan karşıtlığı ile anlatılmaktadır. Uzaylılıarın yazı biçimi çok boyutlu algıya izin veren diresel bir yapıdadır. Hafıza ve kronoloji ilişkisi de önce-sonra bağlantısı ile değil, dairesel biçimde anlatılmaktadır.

Filmin anlatısı Derrida'nın öngördüğü üzere kesin tanımlar ve sınıflandırmalar yapmaktan kaçınılması iletisini aktarmaktadır. Film süresince farklı kültürlerden bilimadamlarının öngörüleri yanlış çıkmış, insana özgü kesin sınıflandırmaların çatışmalara sebep olduğu düşüncesi işlenmiştir. Metinsel düzeyde, yapısökümün öngördüğü üzere tüm varsayımlar ve farklılıkların önplana çıkarılmasını gerektiren tanımlamalar yanlış çıkarken, yalnızca iletişim ve sözün kendisi sabit bir referans olarak varlığını sürdürebilmiştir.

Popüler kültür alanında yapılan çalışmalar, kültür endüstrisi kavramına vurgu yapmaktadır. Kültür endüstrisi kavramı, anlatı sineması ürünlerinin analizi konusunda kullanılabilmektedir. $\mathrm{Bu}$ çerçevedeki bakış, kültür sanat ürünlerinin siyasi, sosyal ve ekonomik alandaki güç odaklarının etkisiyle biçimlendirildiğine vurgu yapmaktadır. Tür sineması geniş toplumsal kitlelerin erişimine açık bir alandır. Bilimkurgu filmlerinin küresel, bireysel ölçekteki tema tercihleri ve geleceğe ilişkin öngörüleri kültür endüstrisi anlamındaki bağları açıkça ortaya koymak için yeterli olmasa da türün siyasi, sosyal ekonomik anlamda söylemlere yer verdiğini göstermektedir. Konuyla ilgili yapılacak ekonomi-politik ve sosyolojik analizler bilimkurgu filmlerinin üretim sürecindeki temel bakış açılarını vurgulamak için önemlidir. Bilimkurgunun anlatı düzeyindeki analizler ise türün kendisine olan izleyici ilgisini canlı tutabilmek için güncel sorunlara ve insanlığın ürettiği mitlere vurgu yaptığını göstermektedir. Bilimkurgunun, anlatı sineması kapsamındaki temel özelliklerini korurken türe özgü kalıplarını popülaritesini korumak için farklı dönemlerde değiştirdiğini söylemek mümkündür. Türe dahil filmlerin güncel bireysel, sosyal ve kültürel temalara vurgu yaptı̆ğ temaların tespit aşamalarından bağımsız olarak yapılan analizlerde ulaşılabilecek bir sonuç olarak değerlendirilmektedir. Yönetmenlerin ilgi alanlarıve estetik bakışlarının bilimkurgu alanındaki filmlerin üretiminde rol oynadığını söylemek mümkündür.

Bilimkurgu türü değişen izleyici ilgisi, sektörel tercihler, sosyal ve kültürel şartlara bağlı olarak diğer film türleriyle etkileşime girebilmekte, ele aldığı konular ve anlatı biçimi değişebilmektedir. Sinemayı etkileyen endüstriyel yapının tür sinemasına etkilerinin analiz edilmesi sinema dişındaki farklı kültürel ve sosyolojik alanlardaki referansların anlaşılması açısından önemlidir. Bu bağlamda, 
tür sinemasının örneklerinin farklı yaklaşımlarla incelenmesinin kültür endüstrisinin tercihlerinin ve nedenlerinin ortaya konulması ve değerlendirilmesi bakımından sürdürülmesi önerilmektedir.

\section{Kaynaklar}

Abisel, N. (1995). Popüler sinema ve türler. İstanbul: Alan Yayınc1lı.

Acar, A. (2017). Sessiz sinema tarihi. İstanbul: Doruk Yayıncılık.

Adorno, T. W. ve Rabinbach, A. G. (1975). Culture industry reconsidered. New German Critique (6), 12-19.

Altman, R. (1984). A semantic/syntactic approach to film genre. Cinema Journal, 23(3), 6-18.

Altman, R. (2008). Tür Sineması. İçinde Nowell-Smith, G. (Ed.), Dünya sinema tarihi. Fethi, A. (Çev., ss. 342-352). İstanbul: Kabalcı Yayınevi.

Baltacı, A. (2019). Nitel Araştırma Süreci: Nitel Bir Araştırma Nasıl Yapılır?. Ahi Evran Üniversitesi Sosyal Bilimler Enstitüsü Dergisi, 5 (2), 368-388. DOI: 10.31592/aeusbed.598299

Beyazperde. Denis Villeneuve. http://www.beyazperde.com/sanatcilar/sanatci-27087/ adresinden 31.08.2019 tarihinde erişilmiştir.

Bould, M. (2015). Bilimkurgu. Okan, S. ve Genç, E. (Çev.) İstanbul: Kolektif Kitap.

Buckland, W. (2018). Sinemayı anlamak. Göbekçin, T. (Çev.) İstanbul: Hayalperest Yayınevi.

Calvin, R. (May1s, 2014). Science fiction film theory and criticism. (Oxford University Press) Oxford Bibliographies: $\quad$ https://www.oxfordbibliographies.com/view/document/obo9780199791286/obo-9780199791286-

0088.xml?rskey=LY0llv\&result=1\&q=science+fiction\#firstMatch $\quad$ adresinden $\quad 26.08 .2019$ tarihinde erişilmiştir.

Corrigan, T. (2007). Film eleştirisi el kitabı. Gürata, A. (Çev.) Ankara: Dipnot Yayınları.

Çoker, N. B. (2016). Bilimkurgu sineması 1900-1970. İstanbul: Seyyah Kitap.

Erdoğan, İ. (2012). Pozitivist metodoloji ve ötesi. Ankara: Erk Yayınları.

Erdoğan, İ. ve Alemdar, K. (2002). Öteki kuram. Ankara: Erk.

Fontaine, M. ve Mullen, P. (Ekim, 2017). Denis Villeneuve. (The Canadian Encyclopedia) The Canadian Encyclopedia: https://www.thecanadianencyclopedia.ca/en/article/denis-villeneuve adresinden 31.08.2019 tarihinde erişilmiştir.

Forrest, J. D., Barfield, K. E., ve Barbier, M. K. (Ağustos, 2013). Military science fiction. (Oxford Unversity Press) Oxford Bibliographies: https://www.oxfordbibliographies.com/view/document/obo-9780199791279/obo-

9780199791279-0091.xml?rskey=LY0llv\&result=9\&q=science+fiction\#firstMatch adresinden 25.08.2019 tarihinde erişilmiştir.

Gianetti, L. (2001). Understanding movies. New Jersey: Prentice Hall.

Gomery, D. (2008). Yeni Hollywood. İçinde Smith, G. N. (Ed.), Dünya sinema tarihi. Fethi, A. (Çev., ss. 538-547). İstanbul: Kabalcı Yayınevi. 
Güven, Z. C., ve Serarslan, M. (2018). M. Butterfly Filminin Yapı Sökümcü Analizi. Sinefilozofi Dergisi, 3(6), 39-56.

Hunter, S. D. ve Smith, S. (2015). A Network Text Analysis of David Ayer's Fury. Advances in Language and Literary Studies, 6(6), 29-38.

Ünal, Y. (2015). Dram sanatı ve sinema klasik anlatı yapısının kökenleri. İstanbul: Hayalperest Yayınevi.

Internet Movie Database (IMDb). (2019a). Blade runner 2049: biçak sirti. (IMDb.com, Inc.) Internet Movie Database (IMDb): https://www.imdb.com/title/tt1856101/awards?ref_=tt_awd adresinden 31.08.2019 tarihinde erişilmiştir.

Internet Movie Database (IMDb). (2019b). Doroga $k$ zvezdam. (IMDb.com, Inc.) Internet Movie Database (IMDb): https://www.imdb.com/title/tt0052138/?ref_=nv_sr_6?ref_=nv_sr_6 adresinden 28.08.2019 tarihinde erişilmiştir.

Internet Movie Database (IMDb). (2019c). Metropolis. (IMDb.com.inc) Internet Movie Database: https://www.imdb.com/title/tt0017136/?ref_=nv_sr_1?ref_=nv_sr_1 adresinden 27.08.2019 tarihinde erişilmiştir.

Internet Movie Database (IMDb). (2019d). Un 32 août sur terre. (IMDb.com, Inc.) Internet Movie Database: $\quad$ https://www.imdb.com/title/tt0156248/?ref_=nm_flmg_dr_17 adresinden 31.08.2019 tarihinde erişilmiştir.

Kabaday1, L. (2014). Film eleştirisi "kuramsal çerçeve ve sinemamıdan örnek çözümlemeler". İstanbul: Ayrıntı Yayınları.

Karadeniz, H. (2019). Feminist Edebiyat Eleştirisi ve Hatice Bilen Buğra'nın Mal Sahibi Adlı Hikâyesinin İncelenmesi. Ahi Evran Üniversitesi Sosyal Bilimler Enstitüsü Dergisi, 5 (2), 284298. DOI: $10.31592 /$ aeusbed.589693

Metz, C. (2012). Sinemada anlam üstüne denemeler (Cilt 2). Adanır, O. (Çev.) İstanbul: Hayalperest Yayınevi.

Moran, B. (1999). Edebiyat kuramları ve eleştiri. İstanbul: İletişim Yayınları.

Morningbell. (2019). Denis Villeneuve biography. (IMDb.com, Inc.) Internet Movie Database: https://www.imdb.com/name/nm0898288/bio?ref_=nm_ov_bio_sm adresinden 31.08.2019 tarihinde erişilmiştir.

Newman, K. (2014). 2001: Uzay Maceras1. Kemp, P. (Ed.), Sinemanın Tüm Öyküsü (E. Y1lmaz ve N. Yılmaz, Çev.) içinde (ss. 290-293). İstanbul: Hayalperest Yayınevi.

Nowell-Smith, G. (2008). Sonuç - Yeni Sinema Kavramları. G. Nowell-Smith (Ed.), Dünya sinema tarihi (A. Fethi, Çev.) içinde (ss. 851-861). İstanbul, Kabalcı Yayınevi.

Onur, N. (2011). Kitle kültürü sineması ve b filmi. İstanbul: Hayalperest Yayınevi.

Özön, N. (2008). Sinema sanatına giriş. İstanbul: Agora Kitaplığı.

Özön, N. (1985). Sinema uygulayımı sanatı tarihi. İstanbul: Hil Yayın. 
Reeves, J. (2019). Just imagine. (IMDb.com, Inc.) Internet Movie Database (IMDb): https://www.imdb.com/title/tt0021016/plotsummary?ref_=tt_ov_pl adresinden 28.08.2019 tarihinde erişilmiştir.

Roberts, A. (2006). The history of science fiction. Hampshire: Palgrave Macmillan.

Rutli, E. E. (2016). Derrida'nın Yapısökümü. Temaşa Erciyes Üniversitesi Felsefe Bölümü Dergisi (5), 49-68.

Ryan, M. ve Lenos, M. (2012). Film çözümlemesine giriş. Sonat, E. S. (Çev.) Ankara: De Ki Basım Yayım.

Sartelle, J. (2008). Bir Hollywood Gişe Filminde Düşler ve Kabuslar. İçinde Nowell-Smith, G. (Ed.), Dünya sinema tarihi. Fethi, A. (Çev., ss. 584-596). İstanbul: Kabalcı Yayınevi.

Sobchack, V. (2008). Fantastik Film. İçinde Nowell-Smith, G. (Ed.), Dünya sinema tarihi. Fethi, A. (Çev., ss. 362-371). İstanbul: Kabalcı Yayınevi.

Stam, R. (2014). Sinema teorisine giriş. Salman, S. ve Asatekin, Ç. (Çev.) İstanbul: Ayrıntı Yayınları. Villeneuve, Dennis. (Yönetmen). (2016). Arrival [Film]. Amerika Birleşik Devletleri: Lava Bear Films

Yanık, H. (2016). Yapısöküm Üzerine Birkaç Not. Abant Kültürel Araştırmalar Dergisi (AKAR), 1(2), 91-98. 


\section{Extended Abstract}

\section{Introduction}

Genre films have similar characteristics on certain formal and thematic features. They differ from other genres with their themes and mise en scene features. The thematic similarities of genre films help the audience to follow productions on specific themes. The tools used in films, shooting locations, costumes, lighting, camera angles, and editing techniques are effective factors in creating the characteristics of each genre.

Hollywood film sector's aim to reach more audience was effective in the come up of specific genres. Genre movies' conventions provide the audience with the information on the movie they're going to watch. In terms of the culture industry, genre cinema productions are not differentiated with the specific use of creativity in their production process.

\section{Science Fiction and Arrival's Genre Analysis}

Science fiction movies reach their audience with themes such as technology, space, experiments went out of control and robots. In terms of the credibility of fictional reality, the scientific atmosphere is used as a narrative element. It is possible to say that science fiction films give messages about today's world and social system in various themes. Science fiction films' content affected by the context of the world wars and the circumstances formed before cultural and politic revolutions. It is the life and social order of the society threatened by high-tech armies, aliens or aliens in science fiction films. The heroes restore awareness of traditional values by restoring the social order. It is possible to say that there are productions that question the perception of threats, political and cultural competition, reality, identity, the domination of stronger civilizations on weak cultures and cultural tolerance.

Some of the science fiction films have cultural and political references. The movies may be prepared in terms of propaganda. Like all other genre films, science fiction films interact with other genres. On the other hand, the social circumstances and the original style of the directors are also effective in the realization of the production.

It is possible to link the science fiction genre's interaction with other genres on the basis of its themes. Denis Villeneuve's Arrival (2016) and Blade Runner 2049 (2017) movies can be considered in this context. When aliens and genetic replica themes were used to deal with the concepts such as being human, identity, culture, and memory rather than only being friends, enemies and threats science fiction genre started to interact with mystery and drama.

\section{Results, Discussion and Recommendations}

Arrival (2016) movie is the subject of this research as an example of Villeneuve's mysterious dramatic science fiction style with an original interpretation of the alien concept and the iconography of the science-fiction genre. The film won an Academy Award for best sound editing. In this study, Arrival (2016) directed by Denis Villeneuve was evaluated in the context of science-fiction genre's interaction with other genres and it is aimed to find out if the genre changed in the continuum of social and cultural change. Textual analysis technique was used in the genre analysis of Arrival. Derrida's method of deconstruction was used to determine the structural change of the genre. In the film, the theme of time and chronology was not used in the context of fiction but was used to convey messages within the classical narrative. In this context, the production can be considered within classical narrative cinema patterns.

As a result of the study, it is concluded that the movie Arrival reflects the style of its director, Denis Villeneuve, using dark atmosphere depending on personal traumas. It is possible to say that 
Villeneuve has made a film that proposes global cooperation and communication between different cultures, apart from the sci-fi films with the theme of the cold war, terror and tolerance. Arrival as a science fiction, mystery movie defends the idea that cooperation of developed and developing countries is more valuable than war and conflict and that all cultures need each other in the future.

The concept of the culture industry can also be used in the analysis of narrative cinema products. This perspective emphasizes that cultural and artistic products are shaped by the influence of power centers in political, social and economic fields. Even, exposing the science fiction films' global, individual scale theme preferences and predictions for the future is not enough to clarify its ties with the cultural industry, it shows that the genre includes political, social and economic discourses. The narrative level analysis of science fiction shows that the genre emphasizes on current problems and the myths produced by mankind in order to keep the audience's interest in it alive. It is possible to say that science fiction changed genre-specific patterns in different periods in order to maintain its popularity while preserving the basic features of narrative cinema. As a result of the films' narrative analysis that can be reached regardless of the stages of the films' theme creation process, it can be said that science fiction films emphasize current individual, social and cultural issues. It is possible to say that the directors' interests and aesthetic views play a role in the production of science fiction films.

The approach of deconstruction, which enables the identification of alternative meanings that exist at the text level is guiding. For this reason in this study, the conceptual definition practice envisaged by the concept of differance in deconstruction to explain the structural change in science fiction genre was used. In the context of the analysis of the film made according to Derrida's deconstructive approach; it is possible to say that Arrival's approach to the science fiction genre has redefined its usual admissions.

Science fiction genre may interact with other film genres depending on changing audience interests, sectoral preferences, social and cultural conditions. Analyzing the effects of the industrial structure affecting genre cinema is important for understanding its references in different cultural and sociological fields rather than cinema. In this context, it is recommended that the study of genre cinema be continued in order to reveal and evaluate the cultural industry's preferences and their reasons. 